\title{
Translational Approaches In Cardiovascular Diseases by "Omics"
}

\author{
Vahideh Rabani ${ }^{1}$ and Siamak Davani ${ }^{1,2}$ \\ 1EA 3920, Univ. Bourgogne-Franche Comté, \\ Besançon, France \\ ${ }^{2}$ Laboratoire de Pharmacologie Clinique et \\ Toxicologie, $\mathrm{CHU}$ de Besançon, France
}

*Correspondence: Siamak.davani@univ-fcomte.fr

DOI: https://dx.doi.org/10.21775/cimb.028.001

\begin{abstract}
Cardiovascular diseases are among the leading causes of morbidity and mortality. Despite scientific and technical progress in risk prediction, diagnostics, prognostication and therapy of cardiovascular pathologies, new biomarkers and therapeutic targets remain the subject of intense research to reduce the burden of these diseases.
\end{abstract}

High throughput analyses, termed "omics", are a promising avenue of research. These recently developed technical fields have revolutionized biological and medical research in a very short time. By their interdisciplinary nature, these new methods have already provided a wide vision of cell and tissue pathways and functions. Here, we review how these methods can help to discover new biomarkers and therapeutic targets in cardiovascular diseases.

\section{Introduction}

Biomarkers are molecules implicated in the mechanisms of a pathology, or that can provide information about the severity of a disease or sensitivity to specific therapy. In cardiovascular diseases, many events remain unpredictable and to avoid them, we need more accurate, stable, easily detectable, specific and sensitive biomarkers to improve the diagnosis and prognosis of these pathologies (Napoli, Zullo, Picascia, Infante and Mancini, 2013).

Evidently, biological functions must be studied at system levels. The most important tools in system biology studies are collectively termed "Omics". Combining "Omics" data with other markers, like imaging, statistical analyses, epidemiology and clinical biochemistry, will help to achieve a better understanding of pathophysiological issues underlying cardiovascular diseases (Ray, Reddy, Choudhary, Raghu and Srivastava, 2011). The shift towards the wider use of omics tools in cardiovascular diseases has rapidly gained ground in recent years, due to the application of these techniques to improve our understanding of the molecular mechanisms involved in multifactorial diseases. For example, in 2005, approximately 500 articles were published relating to omics techniques in of cardiovascular-related fields, compared to 6500 published articles in 2015 (Google scholar, search for key words "Omics" and "cardiovascular") (Noorabad-Ghahroodi, Abdi, Zand and Najafi, n.d.). In this review, we focus on these high-throughput analytical techniques termed "Omics" and provide an overview of their utility in discovering new molecules as targets or markers in cardiovascular disease.

\section{Genomics as a starting point}

"Omics" are technologies that make it possible to measure, compare or identify hundreds of molecules within a single sample, in a very short time, with a big field of view. These interdisciplinary fields of study, which call on knowledge in biochemistry, biophysics, mathematics, informatics and biology, have helped to elucidate some pathophysiological issues in diseases over the past decade (Figure 1 ) (O 'Donnell and Nabel, 2011).

Genomics has had a significant impact on current knowledge of diseases and biological mechanisms. Inherited diseases or many childhood disorders and rare diseases have become known thanks to genomics studies. According to a report by $\mathrm{O}$ 'Donnell et al, the main goals of genomics in cardiovascular diseases are to elucidate biological mechanisms and using this knowledge, to personalize medicine and shed light on rare 

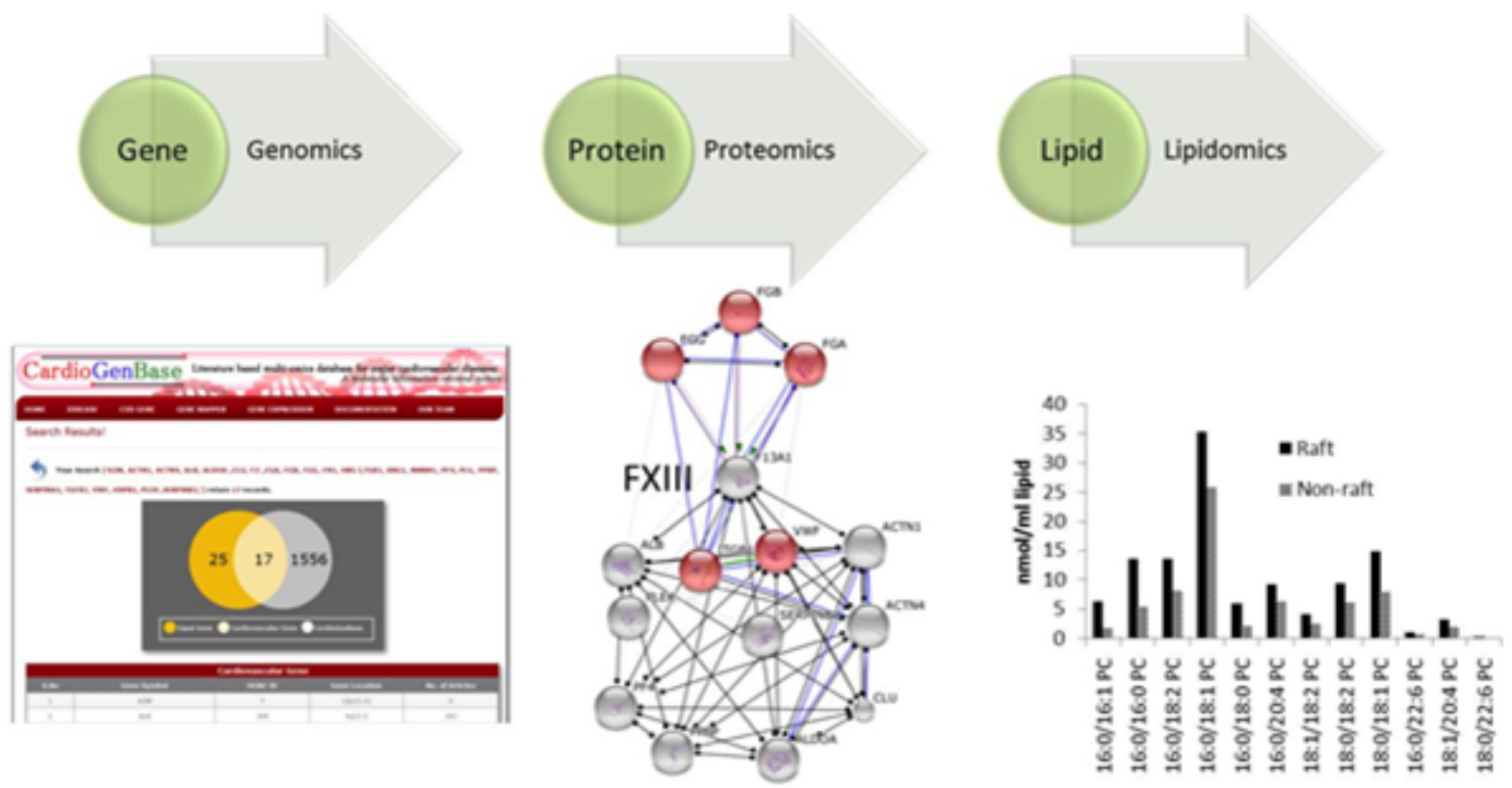

Figure 1. Genomics, proteomics and lipidomics are promising methods in system biology in cardiovascular research. As an example, FXIII (factor 13 of coagulation), can be analyzed at gene level with genomics databases and shows how many genes correspond to a protein network known as cardiovascular related genes. In addition, it can be studied at the level of proteins, by proteomics analyses, showing which proteins FXIII interacts with, when it is on the lipid rafts of platelet. Furthermore, lipidomics analysis can inform about lipid structure and composition (here, only different phosphatidylcholines) of plasma membrane rafts, where FXIII is localized in case of activation, as compared to non-raft parts.

diseases and inherited heart diseases (O 'Donnell and Nabel, 2011). The discovery of mutations affecting the low-density lipoprotein (LDL) receptor, leading to new LDL cholesterol-lowering therapies was one such remarkable application (Goldstein and Brown, 2009).

Currently, several loci are known to be associated with myocardial infarction and coronary artery disease (O 'Donnell and Nabel, 2011; Schunkert et al., 2011). For example, $A B O$ and ADAMTS7 are reportedly associated with coronary atherosclerosis (M. P. Reilly et al., 2011), CNNM2 with high blood pressure and the APOA5 gene cluster with elevated levels of triglycerides and cholesterol (Peden et al., 2011). Gene discoveries have reinforced existing evidence regarding interactions in a number of commonly used cardiovascular drugs; this field of research is sometimes termed pharmacogenomics. For example, variants in CYP2C9 and VKORC1 are implicated in $40 \%$ of response variation to warfarin (Takeuchi et al., 2009). Variations in the cytochrome P-450 enzyme, CYP2C19 is a major factor responsible for non-responsiveness to clopidogrel (Trenk et al., 2008), while variation in the $\beta_{1}$ adrenergic-receptor gene, $A D R B 1$, alters response to beta-blockade in heart failure and a variant in SLC01B1 is associated with statin-related myopathy (Group, 2008; Liu et al., 2012).

In 2015, CardioGenBase proposed a database of major cardiovascular disease-associated research articles ( $V$ et al., 2015; http://www.cardiogenbase.com/index.php). They collected all gene/ proteins related to Major CardioVascular Diseases (MCVDs) published in the literature (Figure 2). The number of genes proposed for each pathology confirmed that there are huge amounts of data on genomics of cardiovascular diseases and today, it is necessary to analyze them systematically. For example, one of the important steps to successful translation of genomics innovation from the laboratory to the clinic relates to the association of a genotype to a phenotype in the population. This can be achieved by a combination of genomics and proteomics, or both, with a clinical phenotype.

It is important to consider that a single gene can produce different proteins, which in turn can be subjected to different post-translational modifications. Therefore genes can provide concrete information about organisms (Tuñón et al., 


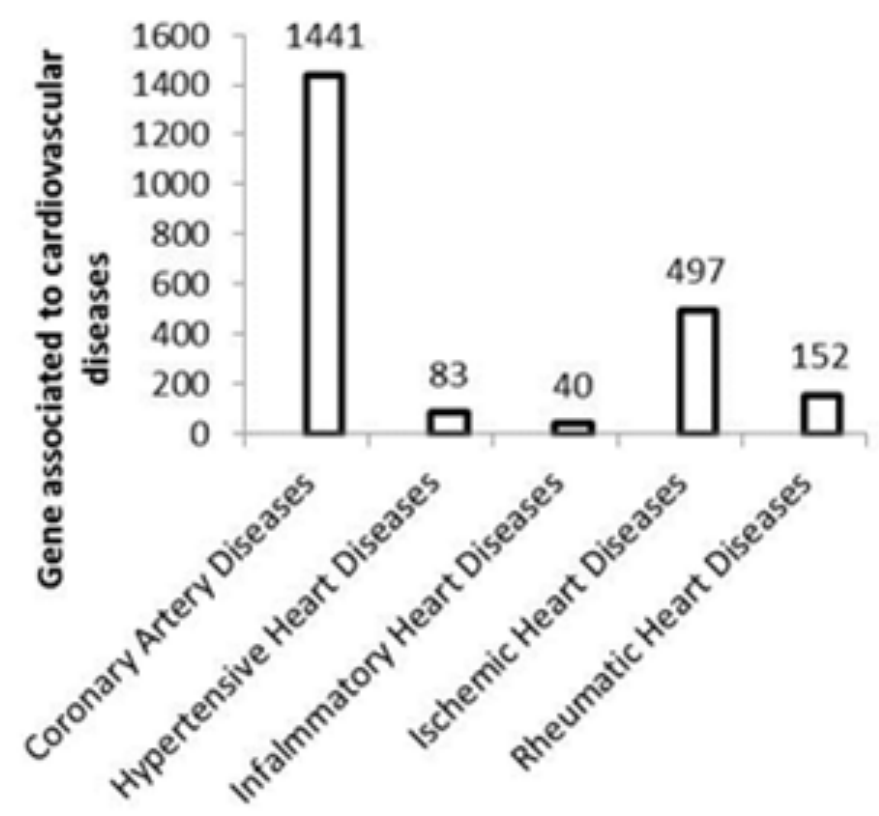

Figure 2. Number of genes proposed to have an association with different MCVDs in literatures based on CardioGeneBase data base.

2010). Genomics with whole genome sequencing prepares a basis for other omics branches, such as proteomics and lipidomics (Arab et al., 2006; Beck, Overgaard and Melholt Rasmussen, 2015; McGregor and Dunn, 2003). In this order, "gene ontology" and "gene annotation" are the principal tools for proteomics data analyses. "Gene annotation" can tell us about the localization and activity of any gene and its product; in other words, it can provide a link between a sequenced gene and its biological function (Aken et al., 2016).

\section{Proteomics: the current center of attention}

Proteomics is based on mass spectrometry (MS), which measures the molecular mass of charged molecules such as proteins or peptides. In this method, proteins or protein fragments are separated according to their physico-chemical properties and their charges. The ratio of mass-to-charge ratios $(\mathrm{m} /$ $z$ ) is compared to current databases to help protein identification and analyses (Aebersold and Mann, 2003). Proteomics is a constantly and rapidly evolving science and utilizes different MS procedures, but reviewing proteomic techniques is beyond the aim of this review and may be found in references (L. Anderson, 2005; Arab et al., 2006;
Duan et al., 2009; Martín-Ventura et al., 2007; Vivanco, López-Bescós, Tuñón and Egido, 2003).

The main goal of proteomics in the search for new biomarkers of cardiovascular disease is to provide a precise and individual risk profile, available in routine practice and to provide a specific and sensitive proteomic approach to detect early signs of pathology. To achieve these goals, we need to dispose of comprehensive protein datasets in physiological and pathological conditions (Napoli et al., 2013) and to combine proteomics results with clinical phenotypes, metabolite changes and genetic haplotype information (Balestrieri, Giovane, Mancini and Napoli, 2008). This combination could also cover genotype-phenotype association (Ozdemir et al., 2009), which is an important aspect in the validation of a new biomarker and for phenotype prediction in population studies (Ritchie, Holzinger, $\mathrm{Li}$, Pendergrass and Kim, 2015). The correlation between genotype and phenotype can prepare a guideline to develop treatment based on genetic testing (Goodsaid and Mattes, 2013).

Most proteomics studies in cardiovascular disease have been performed on plasma from patients. Despite the advantage of the availability of sample 
resources, plasma proteomics is controversial, because of its complexity and dynamics. On the other hand, it is difficult to detect low-abundance proteins in plasma because of the high concentrations of other proteins (the 20 most abundant proteins represent $99.9 \%$ of total plasma protein, like albumin) (Anderson and Anderson, 2002; de la Cuesta et al., 2009). Regardless of these difficulties in plasma proteomics, new candidate biomarkers based on proteomics study on low-abundance plasma proteins have been described. For example, in acute decompensated heart failure (ADHF), bioinformatics analysis of the expression of 103 differential proteins resulted in the identification of quiescin Q6 sulfhydryl oxidase 1 (QSOX-1) as the most promising candidate protein to identify patients with ADHF (Mebazaa et al., 2012). The main activity of QSOX-1 has previously been described as protein folding, production of extracellular matrix, redox regulation and protection from apoptosis, angiogenesis and cell differentiation (Portes et al., 2008). Mebazaa et al showed in a series of animal model and human studies, that the expression of QSOX1, specifically in the left ventricle and left atrium, corresponds to the degree of pressure overload and hypertrophy and subsequent development of ADHF (Mebazaa et al., 2012). Upregulation of myocardial QSOX1 expression was seen only in ADHF and not in patients with acute dyspnea of non-cardiac origin or in patients with stable compensated heart failure. The diagnostic performance of QSOX1 alone was as same as Brain Natriuretic Protein (BNP) and Nterminal proBNP (NT-proBNP) in the entire study population and showed a significant additional diagnostic value when combined with BNP (Doehner, 2012; Mebazaa et al., 2012).

One of the most important adverse cardiovascular events is thrombosis. Research on new biomarkers and potential targets for thrombotic events, to enable risk stratification could focus on plasma, circulating cells or thrombus tissue. Information from these studies have the potential to propose a prothrombic state and represent a link between genotype, environment and disease phenotype (Howes, Keen, Findlay and Carter, 2008). Ramaiola et al studied the proteomics profile of thrombus in in-stent thrombosis (IST) and showed a higher content of structure-related proteins such as gelsolin, actin cytoplasmic 1, tropomyosin and myosin, without changes in fibrin(ogen)-related products. They observed that proteins with enzymatic activity (peroxiredoxin-2, flavin reductase, carbonic anhydrase 1 and alpha enolase) were reduced (Ramaiola et al., 2014). Alonso-Orgaz and coworkers described 108 proteins in human coronary thrombus in patients with ST-segment elevation acute coronary syndrome (STE- ACS). They showed a positive correlation between 5 proteins (fermitin homolog 3, thrombospondin-1, myosin-9, beta parvin and ras-related protein Rap-1b) and CD41, pointing out the importance of focal adhesion pathway activation in platelets participating in thrombus formation (Alonso-Orgaz et al., 2014). Proteomics analysis has also shown that in patients with ST-elevation myocardial infarction, culprit site-derived plasma but not systemic plasma enhanced proteolytic activity towards pigment epithelium-derived factor (PDEF). This proteomics study of coronary thrombus aspirates indicated that PEDF processing is associated with coronary plaque rupture (Distelmaier et al., 2012).

Other sources of information for proteomics are platelets and monocytes involved in thrombosis and atherosclerosis (Tuñón et al., 2010). A study in the proteome of circulating monocytes in patients with non-STE-ACS (Barderas et al., 2007), showed 17 proteins whose expression was altered, as compared with expression in subjects with stable coronary artery disease. Among the proteins showing abnormal expression, levels of antiatherogenic proteins, such as paraoxonase I and HSP70 and anti-inflammatory proteins, such as protein disulfide isomerase were decreased. In contrast, there was overexpression of mature cathepsin D, with pro-atherogenic effects and enolase I, involved in macrophage transformation into foam cells. Other studies in the same context confirm that, in NSTE-ACS patients, atorvastatin 80 $\mathrm{mg} /$ day normalizes expression of HSP70, paraoxonase I, annexin I-which has antiinflammatory properties-and annexin II-involved in spontaneous fibrinolysis (Barderas et al., 2009). It has previously been shown that cathepsin $D$ and HSP70 are biomarkers of atherosclerotic lesions (Vivanco et al., 2007).

Other cell sources for thrombosis proteomics studies are platelets. Platelets do not have any nucleus and therefore, they are controlled by their proteins (García and Senis, 2011). They are upstream of the thrombus formation cascade and can be found in atheromatous plaque ( $\mathrm{Li}$ and Cooley, 1995). There are some proteins like the Dok and RGS families and novel receptors, including CLEC-2 and G6b-B, which were discovered by proteomics analysis in platelets. Analysis of the platelet proteome provides information to identify 
proteins involved in discrete surface platelet function such as platelet adhesion, activation, aggregation and secretion.

A proteomics study on platelets from patients with ACS, compared with stable patients, showed that levels of proteins involved in cytoskeleton formation ( $F$-actin capping, $\beta$-tubulin, $\alpha$-tubulin isotypes 1 and 2 , vinculin, vimentin and two Ras-related protein Rab-7 isotypes), glycolytic reactions (glyceraldehyde-3-phosphate dehydrogenase, lactate dehydrogenase and two pyruvate kinase isotypes) and redox balance (manganese-SOD) were reduced in ACS patients. Proteins associated with cell survival, such as the $\beta$ subunit of the proteasome 1 were also decreased in platelets of patients with ACS compared to stable patients (López-Farré et al., 2011). Another study with similar objectives, comparing protein patterns of platelets from patients with stable or acute coronary atherosclerosis, identified six differentially expressed proteins; two involved in energy metabolism (2-ketoglutarate dehydrogenase $[\mathrm{OGDH}]$ and lactate dehydrogenase [LDH]), three associated with the cytoskeleton-based processes ( $\gamma$-actin, 1B Coronin and Pleckstrin) and one involved in protein degradation (proteasome subunit type 8) (Banfi et al., 2010; Napoli et al., 2013). Some proteomics studies on platelets in cardiovascular diseases are summarized in Table 1.

Most pivotal platelet proteins are situated on its membrane, because platelet activation and aggregation usually require surface contact with the surrounding tissue. Therefore, special interest focuses on this contacting region and hence on the subproteome of the platelet plasma membrane (Burkhart et al., 2012; Lewandrowski et al., 2009; Premsler, Lewandrowski, Sickmann and Zahedi, 2011). In a proteomics study by Lewandrowski and Burkhart, more than 4000 proteins on the plasma membrane of platelets were identified. In the last decade, the introduction of lipid rafts and microdomains as an action platform in membranes has changed our vision of the plasma membrane(Pike, 2003). A cumulating body of evidence suggests that lipid-protein and lipid-lipid interactions in the plasma membrane limit the mobility of membrane proteins and interfere in their localization. Lipid rafts are about $10-200 \mathrm{~nm}$ in lipidordered microdomains enriched with sphingomyelin, glycosphingolipids and cholesterol (Rabani, Davani, Gambert-Nicot, Meneveau and Montange, 2016; Rabani, Davani, et al., 2016; Thomas et al., 2014). It is now established that some platelet proteins, such as P2Y12(Savi et al., 2006) and FXIII (Kasahara et al., 2013)need to be on lipid rafts to be functional.

Using different bioinformatics analysis tools, such as network analyzing could bring new concepts regarding existing data. In our recent study on coagulation FXIII, we showed that its interactive protein network changes after activation of platelets. We showed that FXIII interacts with cytoskeletal proteins such as actin, only after activation of platelets (Rabani, Montange and Davani, 2016). These kinds of interactions also can be considered as therapeutic targets (Ivanov, Khuri and Fu, 2013; M. T. Reilly, Cunningham and Natarajan, 2009; Zinzalla and Thurston, 2009).

In 2015, the American Heart Association (AHA) released a scientific statement on the transformative impact of proteomics on cardiovascular health and disease, in which they summarized the progress that has been made over the last 20 years in proteomics analysis in cardiovascular diseases (Lindsey et al., 2015). This comprehensive review provided a guideline for the use of next-generation proteomics for future scientific discovery in the basic research laboratory and clinical settings.

Globally, proteomics is a promising tool to discover earlier and cheaper new biomarkers and therapeutic targets. However, these biomarkers need biological verification and validation to be considered as a true biomarkers or therapeutic targets. With improving proteomics techniques and procedures and with the completion of the repository map of human proteins ( $85 \%$ complete to date) by the Human Proteome Organization (https://hupo.org/)(Lam et al., 2012), it is possible that this precious method will rapidly move from bench to bedside.

\section{Lipidomics: beyond plasma lipid profile}

Another branch of omics in lipid related diseases (Bou Khalil et al., 2010), which is of potential value in research of biomarker or therapeutic targets is lipidomics. Lipidomics is considered as a subbranch of metabolomics (Haase, Börnigen, Müller and Zeller, 2016). Metabolites are chemical elements whose alteration during metabolism can serve as signatures of biochemical activity. Since most metabolites are lipids (phospholipids, glycerophospholipids and sphingolipids) (Haase et al., 2016) and lipids play a crucial role in most cardiovascular diseases, we focus on lipidomics in this review. 
Table 1: Proteomics study on platelets in cardiovascular diseases.

\begin{tabular}{|c|c|c|}
\hline & Proteomics study & Results \\
\hline Velez et al. & $\begin{array}{l}\text { Compare proteome of } \\
\text { intracoronary versus } \\
\text { peripheral arterial blood } \\
\text { platelets in patient }\end{array}$ & $\begin{array}{l}\text { upregulation of platelet activation } \\
\text { biomarkers at the culprit site }\end{array}$ \\
\hline Van Holten et al. & $\begin{array}{l}\text { Proteome of alpha } \\
\text { granule }\end{array}$ & $\begin{array}{l}\text { activation via PAR } 1 \text { or PAR } 4 \text { does not } \\
\text { affect alpha granule proteome }\end{array}$ \\
\hline Cini et al. & $\begin{array}{l}\text { Compare platelet } \\
\text { proteomics profile of } \\
\text { children with those of } \\
\text { adults }\end{array}$ & $\begin{array}{c}\text { Differences in proteins which participate } \\
\text { in tissue and organ development, cell } \\
\text { proliferation regulation and angiogenesis } \\
\text { processes }\end{array}$ \\
\hline Shah et al. & platelet glycoproteome & $\begin{array}{l}\text { metallopeptidase inhibitor } 1 \text { (TIMP1) is } \\
\text { highly modified by aspirin and correlated } \\
\text { with hyper reactivity of platelets in vitro }\end{array}$ \\
\hline Raphael et al. & $\begin{array}{l}\text { compare platelet } \\
\text { proteomic changes in } \\
\text { platelets from heart } \\
\text { failure subjects }\end{array}$ & $\begin{array}{l}\text { S100A8 is present in the platelets of heart } \\
\text { failure subjects }\end{array}$ \\
\hline Cevik et al. & $\begin{array}{l}\text { Platelet proteomic } \\
\text { profile of patients with } \\
\text { acute ischemic stroke }\end{array}$ & $\begin{array}{c}500 \text { proteins defined, } 83 \text { of these proteins } \\
\text { were found to be significant }\end{array}$ \\
\hline Milioli et al. & $\begin{array}{l}\text { Quantitative proteomics } \\
\text { analysis of platelet- } \\
\text { derived microparticles }\end{array}$ & $\begin{array}{c}\text { distinct protein signatures when } \\
\text { stimulated by different physiological } \\
\text { agonists } \\
3383 \text { proteins, of which } 428 \text { membrane } \\
\text { and } 131 \text { soluble proteins }\end{array}$ \\
\hline
\end{tabular}

Lipidomics is able to quantify hundreds of lipids species in a single sample with various structural and functional roles (Hou, Zhou, Elisma, Bennett and Figeys, 2008). This information improves our understanding of cardiovascular diseases at a level of detail not manageable with classical analytical methods. These technologies are able to identify different lipid compositions; like sphingomyelin and phosphatidylcholine (Rabani, Davani, et al., 2016), different concentrations of molecular lipid species like phosphatidylcholine 18:0/18:1. In addition, in a single sample, they can characterize lipid structure by determination for example of the place of a double bond in a lipid molecule like phosphatidylcholine 16:0/18:1 n9 (Ekroos, Jänis, Tarasov, Hurme and Laaksonen, 2010).

Furthermore, lipidomics can identify lipid cellular distribution and provide information about their biochemical interactions and dynamics (Han and Gross, 2003). This type of lipid data is valuable in cardiovascular research. In this regard, Holčapek et al clustered three groups of people (healthy volunteers, obese people and cardiovascular 
patients) and performed lipidomics analysis of plasma, erythrocytes and lipoprotein fractions (Holčapek et al., 2015). They showed that the two most upregulated lipids in cardiovascular patient groups were 1,3-DG (diacylglycerols) $32: 1$ and 1,3DG 34:1, while the most downregulated species were sphingomyelin $34: 2$ and 1,3-DG $32: 0$ (Holčapek et al., 2015).

Other attempts at cardiovascular risk prediction using lipidomics have revealed a different lipid profile in HIV-positive patients in favor of cardiovascular diseases. Total of 74 lipid species were identified and 8 lipid classes were significantly associated with future cardiovascular events in HIVpositive subjects (Wong et al., 2014).

Bellis et al combined genomics and lipidomics and showed that human plasma lipidome is heritable. They showed a correlation between the lipid component of plasma and polygenes that involve in cardiovascular risk (Bellis et al., 2014). For example, in calcific coronary artery disease (CAD) there is a significant association between singlenucleotide polymorphism and lipid levels, however these relations cannot predict the severity of CAD
(Tsao et al., 2012). The lipid profile of patients with calcific coronary artery disease revealed phosphatidylcholine moieties, with 18-carbon decreased and 20:4 increased (Djekic, Pinto, Vorkas and Henein, 2016). These two lipids have previously been proposed as indicators of disturbed inflammation homeostasis (Vorkas et al., 2015). The levels of these two lipid species and sphingomyelin dysregulation, which is implicated in cell apoptosis, have been proposed as a biomarker of calcific coronary artery disease. However, lipid measurements must be over the long term (57). It is noteworthy that previously, tenascin- $X$ protein was shown to be greatly decreased and alpha-2-HSglycoprotein increased in calcific aortic valves compared with adjacent normal valve tissues (Matsumoto et al., 2012). This is an example of how the combination of knowledge from different sources can yield a concrete result for decoding disease.

In a comparative study of lipidomics profiles of human atherosclerotic plaques, 150 species of lipids were identified in plaque and their interactions as well as differences between plaque lipid expression and control arteries were demonstrated (Stegemann et al., 2011) (Figure 3).
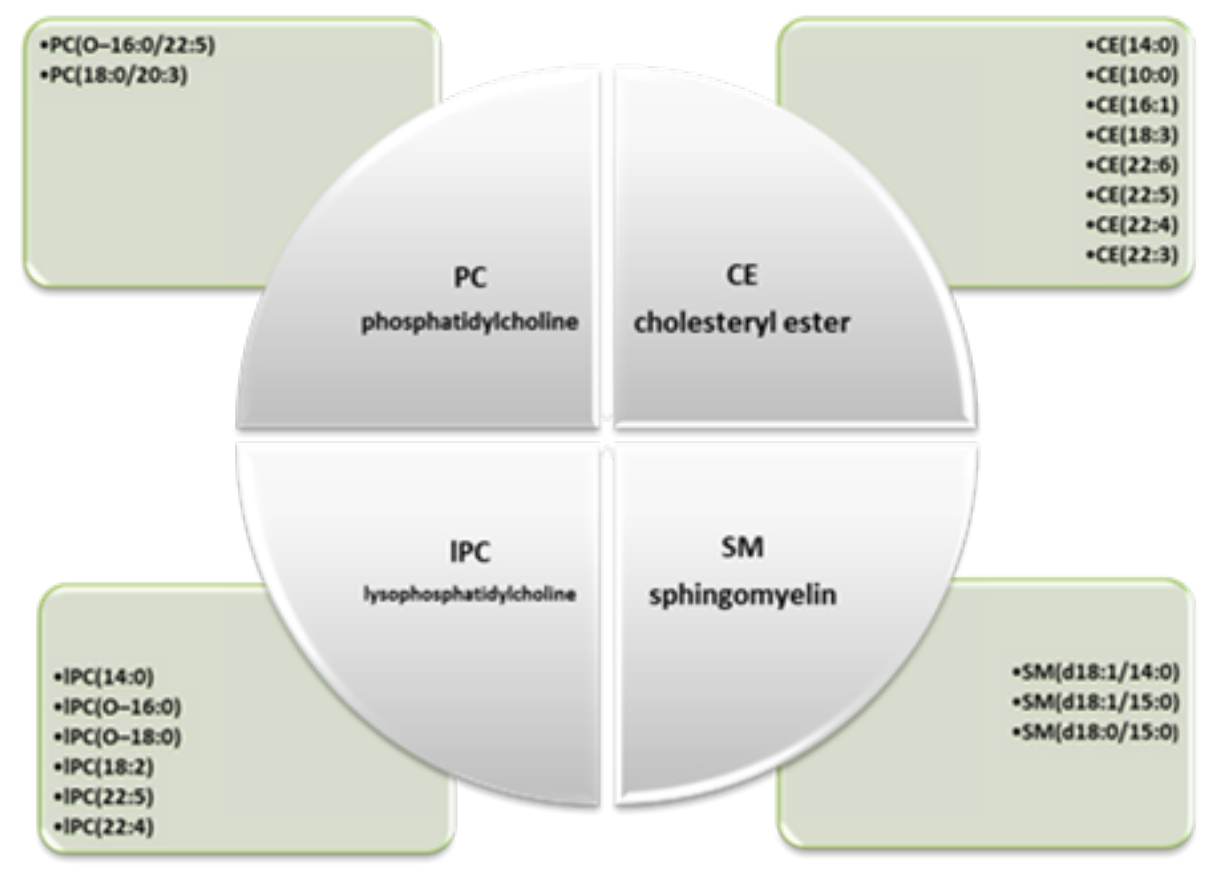

Figure 3. Some of lipid species identified in Human Atherosclerotic Plaques. 
Another important application of lipidomics is in cell membrane research. For example; combining lipidomics and genomics showed that membrane lipids are highly co-regulated. One study revealed a conserved circular lipid network reflecting membrane lipid metabolism, subcellular localization and adaptation mechanisms (Köberlin et al., 2015). Lipidomics provided a good tool for identification of plasma membrane fractions and characterization of these microdomains (Figure 4) by establishing the ratio of cholesterol/sphingomyelin in lipid raft microdomains (Koumanov et al., 2005; Rabani, Davani, et al., 2016; Wolf and Quinn, 2008). These microdomains are the focus of attention in membrane biological research and are implicated in cardiovascular diseases through their participation in platelet activation (Kasahara et al., 2013; Savi et al., 2006), monocyte membrane reorganization (Salvary et al., 2012) and in the mechanisms mediating drug effects (García and Senis, 2011; Zinzalla and Thurston, 2009).

Considering all these aspect of functionality of lipidomics in cardiovascular diseases, we can consider this technique as a very good tool in cardiovascular research toward new biomarkers and therapeutic targets.

\section{Conclusion}

Omics are important tools for the identification of new biomarkers and therapeutic targets in cardiovascular diseases. These methods provide a basis from which to study a biological system. However, this field of research remains young and needs more investigation of the accuracy and applications of the omics techniques. Nonetheless Omics can provide precise idea information about what gene, protein or lipid is valuable for investigation, as well as potentially validating new biomarkers or targets.
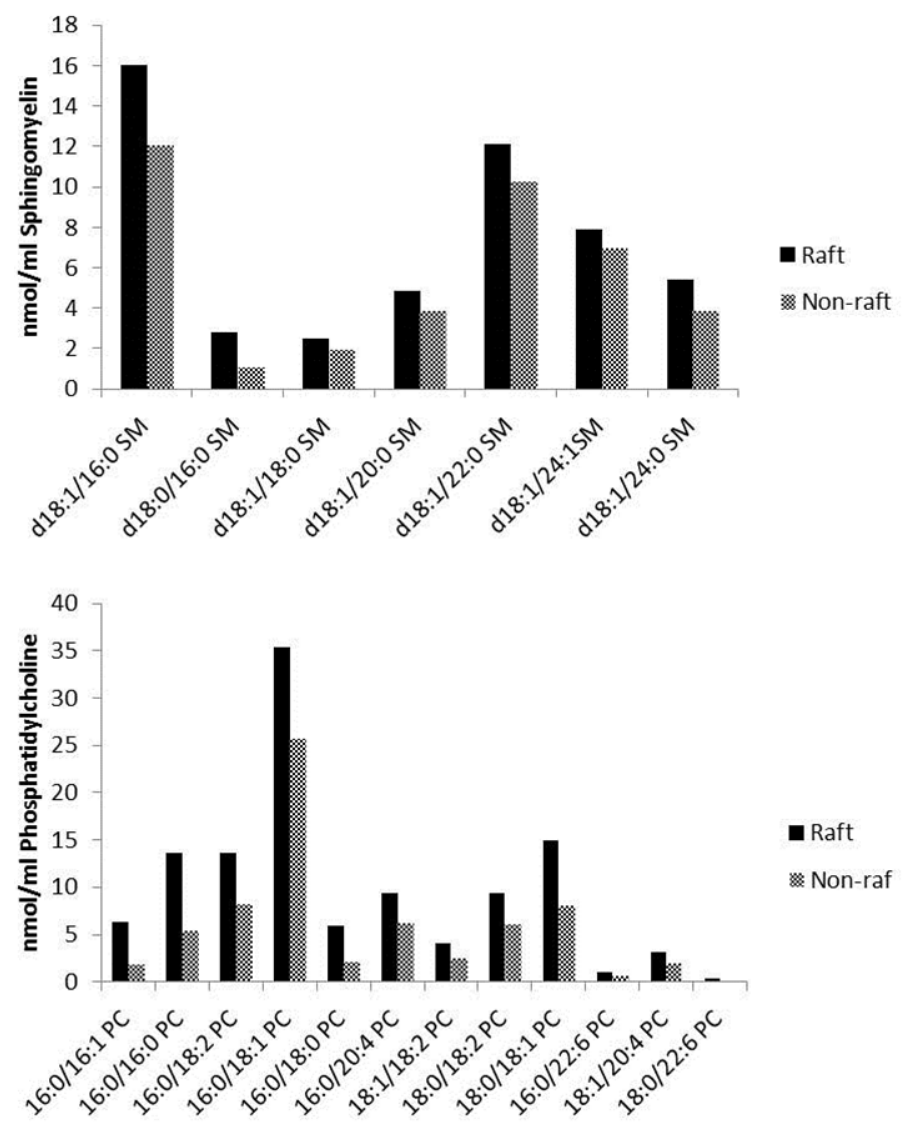

Figure 4. Lipidomics demonstrated variation in lipid species present in raft and non-raft part of platelet membrane. 
Omics will help to strengthen evidence and improve understanding both rapidly and reliably in multifactorial pathologies. Systematic analysis of already Omics data is necessary and helpful to identify populations at risk, provide reliable risk stratification and establish molecular signatures of pathologic conditions.

\section{Acknowledgements}

We thank Mrs Fiona Ecarnot for her critical reading of this manuscript.

\section{References}

Aebersold, R. and Mann, M. (2003). Mass spectrometry-based proteomics. Nature, 422(6928), 198-207. https://doi.org/10.1038/ nature 01511

Aken, B. L., Ayling, S., Barrell, D., Clarke, L., Curwen, V., Fairley, S., ... Searle, S. M. J. (2016). The Ensembl gene annotation system. Database: The Journal of Biological Databases and Curation, 2016. https://doi.org/10.1093/database/ baw093

Alonso-Orgaz, S., Moreno-Luna, R., López, J. A., Gil-Dones, F., Padial, L. R., Moreu, J., ... Barderas, M. G. (2014). Proteomic characterization of human coronary thrombus in patients with ST-segment elevation acute myocardial infarction. Journal of Proteomics, 109, 368-381. https://doi.org/10.1016/j.jprot. 2014.07.016

Anderson, L. (2005). Candidate-based proteomics in the search for biomarkers of cardiovascular disease. The Journal of Physiology, 563(1), 23-60. https://doi.org/10.1113/jphysiol. 2004.080473

Anderson, N. L. and Anderson, N. G. (2002). The human plasma proteome: history, character and diagnostic prospects. Molecular and Cellular Proteomics: MCP, 1(11), 845-867.

Arab, S., Gramolini, A. O., Ping, P., Kislinger, T., Stanley, B., van Eyk, J., ... Liu, P. P. (2006). Cardiovascular Proteomics: Tools to Develop Novel Biomarkers and Potential Applications. Journal of the American College of Cardiology, 48(9), 1733-1741. https://doi.org/10.1016/j.jacc. 2006.06.063

Balestrieri, M. L., Giovane, A., Mancini, F. P. and Napoli, C. (2008). Proteomics and cardiovascular disease: an update. Current Medicinal Chemistry, 15(6), 555-572.

Banfi, C., Brioschi, M., Marenzi, G., De Metrio, M., Camera, M., Mussoni, L. and Tremoli, E. (2010). Proteome of platelets in patients with coronary artery disease. Experimental Hematology, 38(5), 341-350. https://doi.org/10.1016/j.exphem. 2010.03.001

Barderas, M. G., Tuñón, J., Dardé, V. M., De la Cuesta, F., Durán, M. C., Jiménez-Nácher, J. J., ... Vivanco, F. (2007). Circulating Human Monocytes in the Acute Coronary Syndrome Express a Characteristic Proteomic Profile. Journal of Proteome Research, 6(2), 876-886. https://doi.org/10.1021/pr0601990

Barderas, M. G., Tuñón, J., Dardé, V. M., De la Cuesta, F., Jiménez-Nácher, J. J., Tarín, N., ... Vivanco, F. (2009). Atorvastatin modifies the protein profile of circulating human monocytes after an acute coronary syndrome. Proteomics, 9 , 1982-1993. https://doi.org/10.1002/pmic. 200700583

Beck, H. C., Overgaard, M. and Melholt Rasmussen, L. (2015). Plasma proteomics to identify biomarkers - application to cardiovascular diseases. Translational Proteomics, 7, 40-48. https://doi.org/10.1016/j.trprot.2015.01.001

Bellis, C., Kulkarni, H., Mamtani, M., Kent, J. W., Wong, G., Weir, J. M., ... Curran, J. E. (2014). Human plasma lipidome is pleiotropically associated with cardiovascular risk factors and death. Circulation. Cardiovascular Genetics, 7(6), 854-863. https://doi.org/10.1161/CIRCGENETICS. 114.000600

Bou Khalil, M., Hou, W., Zhou, H., Elisma, F., Swayne, L. A., Blanchard, A. P., ... Figeys, D. (2010). Lipidomics era: Accomplishments and challenges. Mass Spectrometry Reviews, 29(6), 877-929. https://doi.org/10.1002/mas.20294

Burkhart, J. M., Vaudel, M., Gambaryan, S., Radau, S., Walter, U., Martens, L., ... Zahedi, R. P. (2012). The first comprehensive and quantitative analysis of human platelet protein composition allows the comparative analysis of structural and functional pathways. Blood, 120(15), e73-82. https://doi.org/10.1182/blood-2012-04-416594

de la Cuesta, F., Alvarez-Llamas, G., Gil-Dones, F., Martin-Rojas, T., Zubiri, I., Pastor, C., ... Vivanco, F. (2009). Tissue proteomics in atherosclerosis: elucidating the molecular mechanisms of cardiovascular diseases. Expert Review of Proteomics, 6(4), 395-409. https://doi.org/ 10.1586/epr.09.60

Distelmaier, K., Adlbrecht, C., Jakowitsch, J., Wagner, O., Gerner, C., Lang, I. M. and Kubicek, M. (2012). Proteomic profiling of acute coronary thrombosis reveals a local decrease in pigment epithelium-derived factor in acute myocardial infarction. Clinical Science (London, England: 
1979), 123(2), 111-119. https://doi.org/10.1042/ CS20110680

Djekic, D., Pinto, R., Vorkas, P. A. and Henein, M. Y. (2016). Replication of LC-MS untargeted lipidomics results in patients with calcific coronary disease: An interlaboratory reproducibility study. International Journal of Cardiology, 222, 1042-1048. https://doi.org/10.1016/j.ijcard. 2016.07.214

Doehner, W. (2012). Diagnostic biomarkers in cardiovascular disease: the proteomics approach. European Heart Journal, 33(18), 2249-2251. https://doi.org/10.1093/eurheartj/ehs187

Duan, X., Young, R., Straubinger, R. M., Page, B., Cao, J., Wang, H., ... Qu, J. (2009). A Straightforward and Highly Efficient Precipitation/ On-Pellet Digestion Procedure Coupled with a Long Gradient Nano-LC Separation and Orbitrap Mass Spectrometry for Label-Free Expression Profiling of the Swine Heart Mitochondrial Proteome. Journal of Proteome Research, 8(6), 2838-2850. https://doi.org/10.1021/pr900001t

Ekroos, K., Jänis, M., Tarasov, K., Hurme, R. and Laaksonen, R. (2010). Lipidomics: a tool for studies of atherosclerosis. Current Atherosclerosis Reports, 12(4), 273-281. https://doi.org/10.1007/ s11883-010-0110-y

García, Á. and Senis, Y. A. (Eds.). (2011). Frontmatter. In Platelet Proteomics (pp. i-xx). John Wiley and Sons, Inc. Retrieved from http:// onlinelibrary.wiley.com/doi/10.1002/97804709402 97.fmatter/summary

Goldstein, J. L. and Brown, M. S. (2009). The LDL Receptor. Arteriosclerosis, Thrombosis and Vascular Biology, 29(4), 431-438. https://doi.org/ 10.1161/ATVBAHA.108.179564

Goodsaid, F. and Mattes, W. B. (2013). The Path from Biomarker Discovery to Regulatory Qualification. Academic Press.

Group, T. S. C. (2008). SLCO1B1 Variants and Statin-Induced Myopathy - A Genomewide Study. New England Journal of Medicine, 359(8), 789-799. https://doi.org/10.1056/NEJMoa0801936

Haase, T., Börnigen, D., Müller, C. and Zeller, T. (2016). Systems Medicine as an Emerging Tool for Cardiovascular Genetics. Frontiers in Cardiovascular Medicine, 3. https://doi.org/ 10.3389/fcvm.2016.00027

Han, X. and Gross, R. W. (2003). Global analyses of cellular lipidomes directly from crude extracts of biological samples by ESI mass spectrometry: a bridge to lipidomics. Journal of Lipid Research, 44(6), 1071-1079. https://doi.org/10.1194/ jlr.R300004-JLR200
Holčapek, M., Červená, B., Cífková, E., Lísa, M., Chagovets, V., Vostálová, J., ... Hill, M. (2015). Lipidomic analysis of plasma, erythrocytes and lipoprotein fractions of cardiovascular disease patients using UHPLC/MS, MALDI-MS and multivariate data analysis. Journal of Chromatography B, 990, 52-63. https://doi.org/ 10.1016/j.jchromb.2015.03.010

Hou, W., Zhou, H., Elisma, F., Bennett, S. A. L. and Figeys, D. (2008). Technological developments in lipidomics. Briefings in Functional Genomics and Proteomics, 7(5), 395-409. https://doi.org/ 10.1093/bfgp/eln042

Howes, J.-M., Keen, J. N., Findlay, J. B. and Carter, A. M. (2008). The application of proteomics technology to thrombosis research: the identification of potential therapeutic targets in cardiovascular disease. Diabetes and Vascular Disease Research, 5(3), 205-212. https://doi.org/ 10.3132/dvdr.2008.033

Ivanov, A. A., Khuri, F. R. and Fu, H. (2013). Targeting protein-protein interactions as an anticancer strategy. Trends in Pharmacological Sciences, 34(7), 393-400. https://doi.org/10.1016/ j.tips.2013.04.007

Kasahara, K., Kaneda, M., Miki, T., lida, K., SekinoSuzuki, N., Kawashima, I., ... Yamamoto, N. (2013). Clot retraction is mediated by factor XIIIdependent fibrin-allbß3-myosin axis in platelet sphingomyelin-rich membrane rafts. Blood, 122(19), 3340-3348. https://doi.org/10.1182/ blood-2013-04-491290

Köberlin, M. S., Snijder, B., Heinz, L. X., Baumann, C. L., Fauster, A., Vladimer, G. I., ... SupertiFurga, G. (2015). A Conserved Circular Network of Coregulated Lipids Modulates Innate Immune Responses. Cell, 162(1), 170-183. https://doi.org/ 10.1016/j.cell.2015.05.051

Koumanov, K. S., Tessier, C., Momchilova, A. B., Rainteau, D., Wolf, C. and Quinn, P. J. (2005). Comparative lipid analysis and structure of detergent-resistant membrane raft fractions isolated from human and ruminant erythrocytes. Archives of Biochemistry and Biophysics, 434(1), 150-158. https://doi.org/10.1016/j.abb. 2004.10.025

Lam, M. P. Y., Vivanco, F., Scholten, A., Hermjakob, H., Van Eyk, J. and Ping, P. (2012). HUPO 2011: The new Cardiovascular Initiative - integrating proteomics and cardiovascular biology in health and disease. Proteomics, 12(6), 749-751. https:// doi.org/10.1002/pmic.201270015

Lewandrowski, U., Wortelkamp, S., Lohrig, K., Zahedi, R. P., Wolters, D. A., Walter, U. and Sickmann, A. (2009). Platelet membrane 
proteomics: a novel repository for functional research. Blood, 114(1), e10-19. https://doi.org/ 10.1182/blood-2009-02-203828

$\mathrm{Li}, \quad$ X. and Cooley, B. C. (1995). Effect of anticoagulation and inhibition of platelet aggregation on arterial versus venous microvascular thrombosis. Annals of Plastic Surgery, 35(2), 165-169; discussion 169-170.

Lindsey, M. L., Mayr, M., Gomes, A. V., Delles, C., Arrell, D. K., Murphy, A. M., ... Srinivas, P. R. (2015). Transformative Impact of Proteomics on Cardiovascular Health and Disease. Circulation, 132(9), 852-872. https://doi.org/10.1161/CIR. 0000000000000226

Liu, W.-N., Fu, K.-L., Gao, H.-Y., Shang, Y.-Y., Wang, Z.-H., Jiang, G.-H., ... Zhong, M. (2012). $\beta 1$ adrenergic receptor polymorphisms and heart failure: a meta-analysis on susceptibility, response to $\beta$-blocker therapy and prognosis. PloS One, 7(7), e37659. https://doi.org/10.1371/journal.pone. 0037659

López-Farré, A. J., Zamorano-Leon, J. J., Azcona, L., Modrego, J., Mateos-Cáceres, P. J., GonzálezArmengol, J., ... Macaya, C. (2011). Proteomic changes related to "bewildered" circulating platelets in the acute coronary syndrome. Proteomics, 11(16), 3335-3348. https://doi.org/ 10.1002/pmic.201000708

Martín-Ventura, J. L., Blanco-Colio, L. M., Tunon, J., Gomez-Guerrero, C., Michel, J.-B., Meilhac, O. and Egido, J. (2007). Proteomics in atherothrombosis: a future perspective. Expert Review of Proteomics, 4(2), 249-260. https:// doi.org/10.1586/14789450.4.2.249

Matsumoto, K.-I., Satoh, K., Maniwa, T., Araki, A., Maruyama, R. and Oda, T. (2012). Noticeable decreased expression of tenascin- $X$ in calcific aortic valves. Connective Tissue Research, 53(6), 460-468.

https://doi.org/10.3109/03008207.2012.702818

McGregor, E. and Dunn, M. J. (2003). Proteomics of heart disease. Human Molecular Genetics, 12(suppl 2), R135-R144. https://doi.org/10.1093/ $\mathrm{hmg} / \mathrm{ddg} 278$

Mebazaa, A., Vanpoucke, G., Thomas, G., Verleysen, K., Cohen-Solal, A., Vanderheyden, M., ... Kas, K. (2012). Unbiased plasma proteomics for novel diagnostic biomarkers in cardiovascular disease: identification of quiescin Q6 as a candidate biomarker of acutely decompensated heart failure. European Heart Journal, 33(18), 2317-2324. https://doi.org/ 10.1093/eurheartj/ehs162

Napoli, C., Zullo, A., Picascia, A., Infante, T. and Mancini, F. P. (2013). Recent advances in proteomic technologies applied to cardiovascular disease. Journal of Cellular Biochemistry, 114(1), 7-20. https://doi.org/10.1002/jcb.24307

Noorabad-Ghahroodi, F., Abdi, S., Zand, A. H. and Najafi, M. (n.d.). HGDB: A web retrieving cardiovascular-associated gene data. International Journal of Cardiology. https://doi.org/ 10.1016/j.ijcard.2017.01.043

O 'Donnell, C. J. and Nabel, E. G. (2011). Genomics of Cardiovascular Disease. New England Journal of Medicine, 365(22), 2098-2109. https://doi.org/ 10.1056/NEJMra1105239

Ozdemir, V., Suarez-Kurtz, G., Stenne, R., Somogyi, A. A., Someya, T., Kayaalp, S. O. and Kolker, E. (2009). Risk Assessment and Communication Tools for Genotype Associations with Multifactorial Phenotypes: The Concept of "Edge Effect" and Cultivating an Ethical Bridge between Omics Innovations and Society. OMICS: A Journal of Integrative Biology, 13(1), 43-61. https://doi.org/ 10.1089/omi.2009.0011

Peden, J. F., Hopewell, J. C., Saleheen, D., Chambers, J. C., Hager, J., Soranzo, N., ... Anand, S. S. (2011). A genome-wide association study in Europeans and South Asians identifies five new loci for coronary artery disease. Nature Genetics, 43(4), 339-U89. https://doi.org/10.1038/ ng.782

Pike, L. J. (2003). Lipid rafts: bringing order to chaos. Journal of Lipid Research, 44(4), 655-667. https://doi.org/10.1194/jlr.R200021-JLR200

Portes, K. F., Ikegami, C. M., Getz, J., Martins, A. P., de Noronha, L., Zischler, L. F., ... Nakao, L. S. (2008). Tissue distribution of quiescin Q6/ sulfhydryl oxidase (QSOX) in developing mouse. Journal of Molecular Histology, 39(2), 217-225. https://doi.org/10.1007/s10735-007-9156-8

Premsler, T., Lewandrowski, U., Sickmann, A. and Zahedi, R. P. (2011). Phosphoproteome analysis of the platelet plasma membrane. Methods in Molecular Biology (Clifton, N.J.), 728, 279-290. https://doi.org/10.1007/978-1-61779-068-3_19

Rabani, V., Davani, S., Gambert-Nicot, S., Meneveau, N. and Montange, D. (2016). Comparative lipidomics and proteomics analysis of platelet lipid rafts using different detergents. Platelets, 27(7), 634-641.

https://doi.org/10.3109/09537104.2016.1174203

Rabani, V., Montange, D. and Davani, S. (2016). Interactive protein network of FXIII-A1 in lipid rafts of activated and non-activated platelets. Platelets, 27(6), 598-602.

https://doi.org/10.3109/09537104.2016.1153621

Ramaiola, I., Cubedo, J., Padró, T., Blasco, A., Goicolea, J. and Badimon, L. (2014). C0430: 
Thrombus Proteomic Profile in Stent-Thrombosis. Thrombosis Research, 133, S16. https://doi.org/ 10.1016/S0049-3848(14)50075-8

Ray, S., Reddy, P. J., Choudhary, S., Raghu, D. and Srivastava, S. (2011). Emerging nanoproteomics approaches for disease biomarker detection: a current perspective. Journal of Proteomics, 74(12), 2660-2681. https://doi.org/10.1016/j.jprot. 2011.04.027

Reilly, M. P., Li, M., He, J., Ferguson, J. F., Stylianou, I. M., Mehta, N. N., ... Rader, D. J. (2011). Identification of ADAMTS7 as a novel locus for coronary atherosclerosis and association of $A B O$ with myocardial infarction in the presence of coronary atherosclerosis: two genome-wide association studies. Lancet (London, England), 377(9763), 383-392. https://doi.org/10.1016/ S0140-6736(10)61996-4

Reilly, M. T., Cunningham, K. A. and Natarajan, A. (2009). Protein-protein interactions as therapeutic targets in neuropsychopharmacology. Neuropsychopharmacology: Official Publication of the American College of Neuropsychopharmacology, 34(1), 247-248. https://doi.org/ 10.1038/npp.2008.167

Ritchie, M. D., Holzinger, E. R., Li, R., Pendergrass, S. A. and Kim, D. (2015). Methods of integrating data to uncover genotype-phenotype interactions. Nature Reviews Genetics, 16(2), 85-97. https:// doi.org/10.1038/nrg3868

Salvary, T., Gambert-Nicot, S., Brindisi, M.-C., Meneveau, N., Schiele, F., Séronde, M.-F., ... Davani, S. (2012). Pravastatin reverses the membrane cholesterol reorganization induced by myocardial infarction within lipid rafts in CD14(+)/ CD16(-) circulating monocytes. Biochimica Et Biophysica Acta, 1821(9), 1287-1294. https:// doi.org/10.1016/j.bbalip.2012.01.017

Savi, P., Zachayus, J.-L., Delesque-Touchard, N., Labouret, C., Hervé, C., Uzabiaga, M.-F., ... Herbert, J.-M. (2006). The active metabolite of Clopidogrel disrupts P2Y12 receptor oligomers and partitions them out of lipid rafts. Proceedings of the National Academy of Sciences of the United States of America, 103(29), 11069-11074. https:// doi.org/10.1073/pnas.0510446103

Schunkert, H., König, I. R., Kathiresan, S., Reilly, M. P., Assimes, T. L., Holm, H., ... Consortium, the Cardi. (2011). Large-scale association analysis identifies 13 new susceptibility loci for coronary artery disease. Nature Genetics, 43(4), 333-338. https://doi.org/10.1038/ng.784

Stegemann, C., Drozdov, I., Shalhoub, J., Humphries, J., Ladroue, C., Didangelos, A., ... Mayr, M. (2011). Comparative lipidomics profiling of human atherosclerotic plaques. Circulation. Cardiovascular Genetics, 4(3), 232-242. https:// doi.org/10.1161/CIRCGENETICS.110.959098

Takeuchi, F., McGinnis, R., Bourgeois, S., Barnes, C., Eriksson, N., Soranzo, N., ... Deloukas, P. (2009). A genome-wide association study confirms VKORC1, CYP2C9 and CYP4F2 as principal genetic determinants of warfarin dose. PLoS Genetics, 5(3), e1000433. https://doi.org/ 10.1371/journal.pgen.1000433

Thomas, P. V., Cheng, A. L., Colby, C. C., Liu, L., Patel, C. K., Josephs, L. and Duncan, R. K. (2014). Localization and proteomic characterization of cholesterol-rich membrane microdomains in the inner ear. Journal of Proteomics, 103, 178-193. https://doi.org/10.1016/ j.jprot.2014.03.037

Trenk, D., Hochholzer, W., Fromm, M. F., Chialda, L.-E., Pahl, A., Valina, C. M., ... Neumann, F.-J. (2008). Cytochrome P450 2C19 681G>A polymorphism and high on-clopidogrel platelet reactivity associated with adverse 1-year clinical outcome of elective percutaneous coronary intervention with drug-eluting or bare-metal stents. Journal of the American College of Cardiology, 51(20), 1925-1934.

https://doi.org/10.1016/j.jacc.2007.12.056

Tsao, C. W., Preis, S. R., Peloso, G. M., Hwang, S.J., Kathiresan, S., Fox, C. S., ... O 'Donnell, C. J. (2012). Relations of long-term and contemporary lipid levels and lipid genetic risk scores with coronary artery calcium in the framingham heart study. Journal of the American College of Cardiology, 60(23), 2364-2371. https://doi.org/ 10.1016/j.jacc.2012.09.007

Tuñón, J., Martín-Ventura, J. L., Blanco-Colio, L. M., Lorenzo, O., López, J. A. and Egido, J. (2010). Proteomic strategies in the search of new biomarkers in atherothrombosis. Journal of the American College of Cardiology, 55(19), 2009-2016. https://doi.org/10.1016/j.jacc. 2010.01.036

V, A., Nayar, P. G., Murugesan, R., Mary, B., P, D. and Ahmed, S. S. S. J. (2015). CardioGenBase: A Literature Based Multi-Omics Database for Major Cardiovascular Diseases. PLOS ONE, 10(12), e0143188. https://doi.org/10.1371/journal.pone. 0143188

Vivanco, F., López-Bescós, L., Tuñón, J. and Egido, J. (2003). Proteómica y enfermedad cardiovascular. Revista Española de Cardiología, 56(3), 289-302.

https://doi.org/10.1016/S0300-8932(03)76865-1

Vivanco, F., Mas, S., Darde, V. M., De la Cuesta, F., Alvarez-Llamas, G. and Barderas, M. G. (2007). 
Vascular proteomics. PROTEOMICS - Clinical Applications, 1(9), 1102-1122. https://doi.org/ 10.1002/prca.200700190

Vorkas, P. A., Isaac, G., Holmgren, A., Want, E. J., Shockcor, J. P., Holmes, E. and Henein, M. Y. (2015). Perturbations in fatty acid metabolism and apoptosis are manifested in calcific coronary artery disease: An exploratory lipidomic study. International Journal of Cardiology, 197, 192-199. https://doi.org/10.1016/j.ijcard.2015.06.048

Wolf, C. and Quinn, P. J. (2008). Lipidomics: Practical aspects and applications. Progress in Lipid Research, 47(1), 15-36. https://doi.org/ 10.1016/j.plipres.2007.09.001
Wong, G., Trevillyan, J. M., Fatou, B., Cinel, M., Weir, J. M., Hoy, J. F. and Meikle, P. J. (2014). Plasma lipidomic profiling of treated HIV-positive individuals and the implications for cardiovascular risk prediction. PloS One, 9(4), e94810. https:// doi.org/10.1371/journal.pone.0094810

Zinzalla, G. and Thurston, D. E. (2009). Targeting protein-protein interactions for therapeutic intervention: a challenge for the future. Future Medicinal Chemistry, 1(1), 65-93. https://doi.org/ 10.4155/fmc.09.12 
